\title{
Pesquisa narrativa com mulheres que usam drogas: uma experiência etnográfica feminista
}

\author{
Isabela Saraiva de Queiroz ${ }^{\mathrm{a} *}$ \\ Marco Aurélio Máximo Prado ${ }^{\mathrm{b} 1}$ \\ aUniversidade Federal de São João del-Rei, Departamento de Psicologia. São João del-Rei, MG, Brasil \\ ${ }^{b}$ Universidade Federal de Minas Gerais, Departamento de Psicologia. Belo Horizonte, MG, Brasil
}

Resumo: Trata-se de pesquisa narrativa inscrita no campo epistemológico feminista, que buscou conhecer a trajetória de vida de mulheres usuárias de crack. Foi realizada uma etnografia multissituada/multilocal, que partiu da escuta de usuárias inseridas num serviço público de saúde mental para, na sequência, seguir duas delas pelos espaços nos quais circulavam, quais sejam, abrigo, escola, equipamentos de saúde, além de suas próprias casas. Como método de coleta de dados foi utilizada a técnica de entrevista narrativa. A escuta das mulheres possibilitou a desarticulação de sentidos fixos e desafiou a inteligibilidade orientadora das práticas de cuidado às pessoas que usam drogas. Foram ressaltados os limites que a condição de usuária de um serviço de saúde mental estabelece à enunciação de um saber válido das mulheres sobre si mesmas, sendo suas narrativas produto do discurso sobre elas elaborado pelo campo da saúde, que institui e prescreve sua própria materialização como usuárias de drogas.

Palavras-chave: mulheres usuárias de drogas, epistemologia feminista, etnografia, entrevista narrativa.

\section{Introdução}

Incorporar o deslocamento da discussão sobre o uso de drogas de um campo que se propõe terapêutico, mas é atravessado por questões morais, para o registro do político é tarefa desafiadora, seja por essa ser uma problemática inscrita na ilegalidade, seja pela proposição de se dar voz a um grupo social até então tido como incapaz de elaborar significados positivos e legitimados socialmente às suas experiências, caracterizadamente marginais. Escutar mulheres que usam drogas aparece, assim, como possibilidade de produção e articulação de narrativas que podem subverter o silenciamento sistemático no qual foram e permanecem inscritas.

Spivak (1987) pautou essa questão há três décadas, ao se perguntar: "Pode o subalterno falar?", questionamento que interroga se as condições de opressão podem dar lugar a expressões políticas de fala, entendidas como a articulação de narrativas não capturadas pelos sentidos e compreensões dominantes. Essa pergunta assim colocada "faz alusão às oposições fala/silenciamento, igualdade/opressão, política/servidão, fundamentais para poder compreender as vicissitudes e as contradições desse processo difícil e penoso de emancipação, quando se luta para transformar as condições de opressão" (Castro, 2011, p. 300). O que está posto, assim, é a premência de que as próprias mulheres que usam drogas falem por si mesmas sobre suas experiências e necessidades.

Tendo em vista as considerações feitas anteriormente, assumimos como hipótese inicial que o uso de drogas por

\footnotetext{
* Endereço para correspondência: isabelasq@ufsj.edu.br

1 Bolsista CNPq
}

mulheres se constitui no interior de uma norma de gênero que estabelece contornos específicos a essa experiência. Assim, por um lado, o uso de drogas por mulheres inscrever-se-ia a partir de um registro de fragilidade, que historicamente lhes atribuiu um lugar de dependência, decorrente da necessidade de proteção e vigilância sobre seu corpo. Por outro lado, também estaria relacionado a uma tentativa de deslocamento dos modos de reprodução das normas estabelecidas pela matriz heterossexual, a partir de práticas notadamente contraditórias às esperadas e por ela determinadas (Queiroz, 2015).

Para investigar essa hipótese, faz-se necessário, contudo, romper os limites da produção de discursos sobre drogas feita pelos especialistas, para ir ao encontro da fala das próprias usuárias a respeito de suas experiências cotidianas e sua relação com as drogas. Portanto, numa tentativa de avançar para além da fala dos atores tidos como produtores de saber legítimo sobre o tema especialistas, pesquisadores e profissionais da área da saúde -, buscou-se escutar as próprias mulheres como enunciadoras diretas da sua experiência.

Para tanto, foi realizada uma etnografia multissituada/multilocal (Fischer, 2011, Marcus, 2001), com o objetivo de investigar diferentes sujeitos, grupos e lugares interconectados entre si, com vistas à caracterização de processos amplos, globalmente distribuídos, que se desenvolvem localmente de formas diferentes. Partiu-se, assim, da escuta de usuárias de drogas inseridas em um serviço público de saúde mental para, na sequência, adentrar no cotidiano de duas delas, "seguindo-as" pelos espaços nos quais circulavam, quais sejam, abrigo, escola, centro de saúde, além de suas próprias casas e ruas circunvizinhas. 


\section{Etnografia multissituada/multilocal e entrevista narrativa: articulações metodológicas na pesquisa social feminista}

A etnografia multissituada (Fischer, 2011) ou multilocal (Marcus, 2001) propõe um deslocamento da investigação etnográfica convencional, focada sobre situações locais, para o exame dos modos como circulam significados, objetos e identidades culturais em espaços difusos. Desse modo, diferentemente da etnografia clássica, que se ocupa da descrição densa de um único grupo (Geertz, 1978), feita após um longo período de imersão em campo, a etnografia multissituada ou multilocal propõe a investigação de diferentes grupos e/ou lugares interconectados entre si, pensando as relações por eles estabelecidas a partir de dinâmicas que ultrapassam sua existência em um mesmo e único local (Fischer, 2011, Marcus, 2001).

Marcus (2001) indica várias formas de fazer uma etnografia multilocal. Neste trabalho foram adotados os esquemas nomeados pelo autor como "seguir as pessoas" e "seguir as tramas" para caracterizar a composição da trajetória de mulheres usuárias de drogas, a partir da compreensão do modo como suas experiências foram sendo produzidas por processos históricos que as situaram no interior de determinados discursos.

"Seguir as pessoas" é, para Marcus (2001), a maneira mais óbvia e convencional de materializar uma etnografia multilocal. Trata-se de seguir e permanecer com os movimentos de um grupo particular de sujeitos iniciais, passando por múltiplos lugares de modo a conhecer o que se encontra fora do seu cenário de origem. Isso permite ao pesquisador analisar o que ocorre com os sujeitos em lugares diversos. Para Marcus (2001), "seguir as tramas, histórias ou biografias" é também uma rica fonte de conexões, associações e relações acerca dos objetos de estudo multilocais, uma vez que tramas e histórias de vida narradas individualmente podem revelar associações inesperadas entre lugares e contextos sociais, sendo guias potenciais na realização de observações e análises etnográficas que, de outra forma, permaneceriam invisíveis.

O autor também analisa o engajamento do pesquisador na etnografia multilocal, apontando que, nela, ele se encontra às voltas com compromissos pessoais muitas vezes contraditórios, os quais geram conflitos e se resolvem "não ao se refugiar no papel de antropólogo acadêmico distanciado, mas sendo uma espécie de etnógrafo ativista, renegociando identidades em diferentes lugares enquanto aprende-se mais sobre eles" (Marcus, 2001, p. 123).

Evidencia-se, dessa forma, o caráter ético-político da investigação etnográfica multilocal que, ao exigir do pesquisador um movimento entre lugares e níveis sociais distintos, impregna a investigação de um caráter ativista. Nas palavras de Marcus (2001): "falo de um ativismo muito específico e circunstancial às condições postas pela investigação multilocal. Trata-se de colocar em prática o slogan feminista de que a política é algo pessoal" (p. 123).

Na etnografia multissituada aqui realizada seguimos pessoas e tramas por múltiplos lugares, tendo como fio condutor inicial dos deslocamentos as participantes de um grupo de mulheres de um serviço público de atenção a usuários/as de drogas. Como método para coleta de dados nos encontros com as mulheres, tanto quando estávamos no grupo de mulheres como depois, quando fomos ao seu encontro em outros espaços da cidade, foi utilizada a técnica de entrevista narrativa (Schutze, 1992), cujo objetivo principal é reconstruir a dinâmica da interação entre processos biográficos individuais e mecanismos coletivos. Tal escolha metodológica se deu por considerarmos que a forma narrativa apresenta uma estrutura que permite às pessoas conferir sentido às experiências pessoais e coletivas, constituindo a ideia que fazem sobre si mesmas ao longo da vida, ordenando o vivido, organizando a memória do passado e orientando a consciência do narrador e sua ação futura (Brandão \& Germano, 2009). Germano e Silva Serpa (2008) apontam ainda que, diferentemente do raciocínio lógico das ciências, "o raciocínio narrativo não almeja uma (suposta) verdade histórica ou factual, mas a 'verdade narrativa' que uma pessoa ou grupo concebe mediante a organização dos eventos da vida em uma intriga compreensível ou verossímil" (p. 13). Trata-se, assim, de assumir o relato de um/a narrador/a sobre sua existência através do tempo, de modo que ele/a possa contar livremente sua vida e imprimir ao relato suas próprias categorias. Nesse sentido, deve-se deixar claro que no trabalho com histórias de vida a interferência do pesquisador deve ser mínima.

Segundo Bruner (1997, p. 99), a heterogeneidade dos mundos sociais e da experiência temporal pode ser evidenciada no pensamento e no texto narrativo e, uma vez assumida a visão narrativa, é possível indagar: "Por que uma história é contada e não outra?”. É nesse ponto que as hierarquias políticas e sociais se fazem presentes, estabelecendo quais devem ser as concepções "oficiais" do si-mesmo. Nesse sentido, "as críticas feministas escreveram copiosamente nos últimos anos sobre o modo pelo qual a autobiografia das mulheres foi marginalizada pela adoção de um cânone absolutamente masculino de escrita autobiográfica" (Bruner, 1997, p. 99). A epistemologia feminista denuncia, assim, a maneira como as concepções e práticas hegemônicas de produção de conhecimento sistematicamente desconsideraram as mulheres e outros grupos socialmente discriminados (Harding, 1987). Para Vargas (2012), as teorias assim produzidas "invisibilizam as atividades e os interesses das mesmas e as relações de poder desiguais que vivenciam, além de não atenderem às [suas] reais necessidades" (p. 33).

Sobre isso, Longino (1987) lembra que as considerações políticas constituem forças relevantes na produção científica, capazes de moldar o raciocínio dedutivo e o conteúdo do conhecimento produzido. 
Desse modo, comprometer-se com uma ciência feminista requer a ruptura com a ideia de ciência neutra, assumindo as posições políticas presentes em nossas escolhas metodológicas. Decorre disso também a necessidade de assumirmos que não há determinado método capaz de garantir a elucidação de uma suposta "natureza da mulher", uma vez que, concordando com Haraway (2009):

Não existe nada no fato de ser 'mulher' que naturalmente una as mulheres. Não existe nem mesmo uma tal situação - 'ser' mulher. Trata-se, ela própria, de uma categoria altamente complexa, construída por meio de discursos científicos sexuais e de outras práticas sociais questionáveis (p. 47).

Desse modo, tendo em vista as questões metodológicas apresentadas e considerando nossa inscrição no campo epistemológico feminista, nesta pesquisa privilegiamos as narrativas de mulheres sobre suas trajetórias de vida e uso de drogas, escolha que reflete uma posição política no sentido de fazer emergir a fala das mulheres sobre si mesmas. Tal escolha, mais do que intentar significar uma metodologia específica capaz de revelar a "natureza" do que se passa com as mulheres, justifica-se por refletir uma das ideias centrais da epistemologia feminista, qual seja, a de que o sujeito do conhecimento é um sujeito situado, isto é, um sujeito que tem uma perspectiva própria daquilo que conhece, de si mesmo e dos outros sujeitos cognoscentes (Vargas, 2012). Trata-se, portanto, da adoção de princípios e práticas de pesquisa capazes de proporcionar espaço de fala a sujeitos subalternizados, historicamente silenciados por práticas científicas objetivistas. Uma escuta posicionada da fala das mulheres, assim, requer metodologias que possibilitem a imersão em situações de pesquisa que não excluam as tensões, ressonâncias, transformações, resistências e cumplicidades. "Estou argumentando a favor de políticas e epistemologias de alocação, posicionamento e situação nas quais parcialidade e não universalidade é a condição de ser ouvido nas propostas a fazer de conhecimento racional" (Haraway, 2009, p. 30).

A seguir, passaremos então ao relato de parte da nossa experiência etnográfica com mulheres que usam drogas, produzida a partir da discursividade narrativa e de princípios epistemológicos e metodológicos feministas.

\section{Narrativas de mulheres em grupo: coletivização da experiência e impasses institucionais}

A primeira etapa da pesquisa consistiu na realização de encontros com um grupo de mulheres que frequentavam a permanência-dia de um Centro de Atenção Psicossocial de Álcool e outras Drogas (Caps-ad)².

2 Todo o trabalho de campo da tese da qual o artigo aqui apresentado deriva foi submetido e aprovado pelo Comitê de Ética e Pesquisa da Universidade Federal de Minas Gerais (CEP-UFMG), tendo o projeto
O Caps-ad é um serviço 24 horas que oferece tratamento ambulatorial, em meio aberto, com plano terapêutico individualizado de acordo com as necessidades avaliadas para cada indivíduo. Fornece atenção contínua a pessoas com necessidades relacionadas ao uso de drogas durante todos os dias da semana, inclusive finais de semana e feriados. Conforme as políticas públicas de saúde vigentes, o Caps-ad utiliza a estratégia de redução de danos, não sendo exigida abstinência para inserção no tratamento. Procura adequar a oferta de serviços às necessidades dos usuários, recorrendo a tecnologias de baixa exigência, tais como: adaptação dos horários às especificidades de cada usuário, acolhimento de usuários mesmo sob efeito de substâncias, dispensação de insumos de proteção à saúde (agulhas e seringas limpas, preservativos, etc.), entre outras. Conforme a necessidade, além da permanênciadia (PD) também pode ser ofertada a utilização de leitos de hospitalidade noturna (HN) como opção terapêutica, havendo ainda assistência aos familiares dos usuários, com orientação e apoio especializados (Brasil, 2012).

Foram realizados 21 encontros do grupo de mulheres, durante nove meses, no período de setembro de 2011 a junho de 2012, do qual participaram 23 mulheres e 2 (duas) travestis. Os encontros do grupo tiveram como foco as narrativas das mulheres sobre si mesmas, num processo de produção de sentidos de caráter coletivo e interativo. Conforme Spink e Medrado (2004), "a produção de sentidos não é uma atividade cognitiva intraindividual, nem pura e simples reprodução de modelos predeterminados. Ela é uma prática social, dialógica" (p. 42). Tal processo fez emergir no grupo a possibilidade de (re)construção de discursos historicamente desqualificados e invisibilizados pela lógica hegemônica presente nos pressupostos e práticas científicas. Nesse sentido, buscou-se "lançar luzes sobre práticas sexistas não percebidas, aceitas como naturais/ normais; sobre a 'cegueira de gênero' das políticas e das instituições, que tendem a excluir, ignorar, invisibilizar e/ou silenciar as mulheres, gerando uma ordem social desigual e discriminatória" (Vargas, 2012, p. 5-6).

Alternativas metodológicas como a que o grupo de mulheres coloca possibilitam aos sujeitos refletir sobre "a permanente interação entre a maneira pela qual entendem o mundo e quem eles são enquanto pessoas historicamente situadas" (Saffioti, 1991, p. 150). Dessa maneira, o esforço metodológico para a produção de conhecimentos que possam se constituir como alternativa à ciência hegemônica caracteriza-se, entre outras coisas, por um desafio constante à objetividade, concebida como separada da subjetividade, e pela negação do caráter não científico da experiência.

Assim, através da constituição do que aqui denominamos grupo dispositivo (Barros, 2007), foram compartilhadas histórias de vida cujas experiências de

de pesquisa sido registrado na Plataforma Brasil sob o número CAAE: 21135213.0.0000.5149. 
violência emergiram tecendo um pano de fundo para sentidos comuns elaborados pelas participantes sobre suas trajetórias. Ao mesmo tempo, o compartilhamento de suas histórias no grupo também permitiu às mulheres a coletivização da experiência e a desconstrução de explicações individualizantes para o uso de drogas.

Nesse sentido, cabe dizer que os grupos dispositivos têm o potencial de se constituir como uma via de emergência do político, uma vez que forçam processos de desindividualização, privilegiando a dimensão coletiva da experiência (Barros, 2007). Importa acentuar contudo que, ainda que o grupo dispositivo guarde uma potência virtualmente libertária, esta não é garantida de antemão, podendo-se recair em práticas de sujeição. Pode-se dizer, portanto, que a construção do conhecimento e da mudança só é possível a partir da (re)construção dos próprios agentes envolvidos, pesquisadores e pesquisados. E foi assim que, por meio da interpelação coletiva das relações de subordinação e opressão às quais estavam submetidas e do reconhecimento dos lugares de fragilidade e insuficiência historicamente a elas atribuídos, o grupo potencializou nas mulheres participantes o questionamento da sua condição de gênero.

Rocha e Aguiar (2003) apontam, contudo, que as múltiplas determinações das posições de sujeito presentes no grupo impedem o que poderia ser nomeado como um estado privilegiado de interação no qual se pudesse levar o outro a ser "conscientizado". Faz mais sentido, portanto, "falar num confronto de diferentes subjetividades, o que concederia uma importância maior à construção de espaços públicos de discussão e debate onde essas diferentes subjetividades tivessem a oportunidade de se defrontarem" (Silva, 1993, p. 130).

Sobre isso, a visão descentralizada e multidimensionada de sujeito como entidade dinâmica e mutante, situado em um contexto de transformação constante, mostra-se fundamental, sendo apresentada por Braidotti (2002) a partir do conceito de subjetividade nomade, que "tem a ver com a simultaneidade de identidades complexas e multidimensionadas" (p. 30), cabendo salientar que estar num campo de debate feminista acarreta o reconhecimento da prioridade do gênero na estruturação dessas relações complexas.

É assim que assumimos nesse trabalho a importância de se ter em conta a particular localização de cada mulher, tal como proposto por Rich (2002) no ensaio "Notas para uma política da localização", buscando conjugar, a um só tempo, "uma certa ideia mais ou menos universal sobre aquilo que nos une enquanto mulheres e uma ideia individualizada do que é ser mulher, numa geopolítica específica, num determinado espaço socioeconômico" (Pereira, 2009, p. 74).

Por fim, tendo em vista os pressupostos do feminismo como campo intelectual e sua tentativa de compreensão e deslocamento dos poderes científicos e acadêmicos constituídos, assumimos aqui uma ruptura com a ideia de neutralidade científica, fundamentando nosso trabalho na noção de saber situado, que define um olhar abertamente interessado sobre o objeto de pesquisa. Conforme Foucault (1999), trata-se de "fazer que intervenham saberes locais . . contra a instância teórica unitária que pretenderia filtrá-los, hierarquizá-los, ordená-los em nome de um conhecimento verdadeiro, em nome dos direitos de uma ciência que seria possuída por alguns" (p. 13). É assim que a perspectiva feminista "introduz e exige a construção do objeto a partir de um olhar situado ... o sujeito que se diz metodologicamente feminino e/ou feminista jamais passará por uma fala neutra" (Machado, 1994, p. 22).

É, portanto, a partir do referencial teórico-metodológico do campo de estudos feministas que as experiências das mulheres com o uso de drogas, compartilhadas nos encontros do grupo realizado, são analisadas nesta pesquisa. Temos assim que dos encontros do grupo de mulheres no Caps-ad emergiram dois grandes grupos de narrativas: (1) Narrativas de experiências de impotência e submetimento, efeito de violências produzidas pela assimilação da norma de gênero heterossexual, nas quais o uso de drogas aparece como um remédio para o sofrimento ou como decorrência dele; (2) Narrativas de questionamento da norma de gênero heterossexual, nas quais o uso de drogas aparece como uma possibilidade de fissura ou tentativa de subversão dessa mesma norma (Prado \& Queiroz, 2012).

Assim, nos dois grupos de narrativas identificados, as situações comumente descritas pelas usuárias como associadas ao uso de drogas reproduzem desigualdades de gênero sustentadas por prescrições que atribuem às mulheres uma condição de insuficiência e fragilidade. Exemplos disso foram suas justificativas para o uso de drogas, fundamentadas nas noções de descontrole emocional, saúde mental debilitada, frustração afetiva etc. Só muito pontualmente apareceram narrativas de uso de drogas associadas à experimentação com o corpo ou à recreação, justificativas comumente citadas por homens usuários. Importa lembrar que o próprio conhecimento médico se construiu, em grande medida, a partir de um pressuposto de fragilidade do corpo da mulher, o que estabeleceu práticas corporais específicas, quase sempre convencionadas a espaços sociais regidos pela proteção e controle (Victora \& Knauth, 2004).

Cabe dizer que nossa inserção em um serviço de saúde trouxe implicações decisivas à tentativa de ouvir as mulheres. $\mathrm{O}$ fato de estarem submetidas a um tratamento, mesmo que em um serviço aberto pautado no paradigma da redução de danos, já as caracterizava como pessoas sob tutela institucional decorrente de uma dada caracterização de uso "problemático" de drogas. Assim, não bastasse o fato de sua possibilidade de fala estar limitada pelas prescrições da instituição, todo o aparato médico de controle dos corpos e modos de vida que ditava os contornos possíveis para as experiências naquele espaço também limitava nossa possibilidade de escuta (Foucault, 1987, 1988). Daí que, mesmo tendo ido 
ao encontro das mulheres, suas narrativas, produzidas dentro daquele espaço específico, eram fruto de um discurso sobre si mesmas elaborado pelo campo da saúde, que instituía e prescrevia sua própria materialização como usuárias de drogas. É nesse sentido que Butler (2006) pontua que "quando Foucault afirma que a disciplina 'produz' indivíduos, não só quer dizer que o discurso disciplinar os dirige e os utiliza, mas também que ativamente os constitui" (p. 80).

\section{Desestruturando narrativas: tentativas de borrar trajetórias institucionalizadas}

A segunda etapa da pesquisa fora definida, portanto, a partir da compreensão de que havia no interior da instituição uma produção de narrativas estabelecida como efeito do discurso dos profissionais de saúde sobre as mulheres. Desse modo, numa tentativa de acessar produções subjetivas que de alguma forma pudessem escapar das prescrições normativas, estabelecemos a "rua" como campo, procurando captar nuances nos discursos das mulheres que não podiam ser percebidas nas narrativas produzidas no grupo realizado no interior do Caps-ad.

A tentativa de ir ao encontro das mulheres em espaços não institucionalizados, contudo, revelou-se mais complexa do que o previsto, devido a um fator fundamental: de algum modo, todas aquelas mulheres se encontravam sob alguma tutela institucional, especialmente nos campos da saúde e assistência social. Suas trajetórias indicavam uma peregrinação por serviços de saúde - centros de saúde, Unidades de Pronto Atendimento (Upa), Centros de Atenção Psicossocial (Caps), hospitais - e por equipamentos da assistência social, como Centros de Referência de Assistência Social (Cras), Centros de Referência Especializados de Assistência Social (Creas) e abrigos transitórios. A essas instituições apresentavam demandas diversas: realização de exames, acesso a medicamentos, consulta com especialistas, atendimentos de urgência e tratamento de doenças crônicas. Na assistência social, buscavam acessar benefícios - como auxílio-doença, bolsa-família e aluguel social - ou informações sobre a retirada de documentos e oportunidades de emprego, entre outras.

Acessar uma narrativa que não fosse efeito das instituições parecia se apresentar, portanto, como algo irrealizável. No entanto, acreditávamos que algumas nuances poderiam ser exploradas ao expandir o território de produção de discursos das mulheres usuárias. Assim, demos início à tentativa de "borrar" as narrativas institucionalizadas, trazendo para a cena elementos de fala que, além de serem inevitavelmente atravessados por instituições, também provocassem fissuras nos discursos produzidos por elas. Inspirados por essa tentativa, iniciamos a segunda etapa da pesquisa de campo, agora não mais buscando estar "fora" das instituições, mas "circulando" por elas.
A etnografia multilocal ou multissituada apareceu, então, como estratégia metodológica capaz de possibilitar o acesso às trajetórias e fios que constituíam a circulação das mulheres usuárias por esses diversos espaços. Assim, por meio da ação de "seguir" as tramas e histórias de vida das mulheres, narradas individualmente, poderia ser possível revelar o que ocorria com esses sujeitos tomados coletivamente, através da associação entre lugares e contextos sociais diversos.

A escolha da técnica da entrevista narrativa como método de coleta de dados justificou-se por acreditarmos que o relato autobiográfico das mulheres sobre suas trajetórias poderia fornecer narrativas capazes de, conforme proposto por Scott (1999), elucidar os processos históricos que, através do discurso, posicionaram-nas como sujeitos e produziram suas experiências. Dessa forma, cabe ressaltar, mais do que acessar as experiências das mulheres que usam drogas, buscou-se através dos relatos autobiográficos identificar o modo como essas mesmas mulheres foram constituídas por suas experiências. Para Josso (2006), adotar os relatos de história de vida como metodologia fundamenta-se em dois paradigmas, "o paradigma de um conhecimento fundamentado sobre uma subjetividade explicitada e o paradigma de um conhecimento experiencial, que valoriza a reflexividade produzida a partir de vivências singulares" (p. 21).

Como discutido anteriormente, tais paradigmas aproximam-se dos pressupostos das metodologias feministas, que consideram a fala das mulheres sobre si mesmas essencial para qualquer produção de conhecimento que se queira crítica ao padrão hegemônico de ciência. Buscamos, portanto, ao "seguir" duas mulheres que haviam participado do grupo realizado no Caps-ad - Cleide e Célia ${ }^{3}$ - em seus espaços cotidianos, ir ao encontro das vozes sempre plurais e inacabadas de sujeitos subalternizados, historicamente silenciados por práticas científicas objetivistas. Foi assim que, acessadas em sua diferença, tais mulheres puderam causar uma fissura nos saberes hegemonicamente construídos sobre elas, revelando, através da experiência constitutiva da sua posição subjetiva, outras inteligibilidades possíveis para sua experiência como usuárias de drogas.

\section{Resultados}

Cleide era uma jovem de 23 anos risonha e descontraída. Ela havia participado do grupo de mulheres no Caps-ad com interesse, mas pouca implicação, limitando-se nos encontros a rir das narrativas das outras usuárias. Entrou na lista das mulheres com as quais poderíamos fazer contato na segunda etapa da pesquisa por cumprir os critérios estabelecidos: ter participado de pelo menos dois encontros do grupo e ser usuária de crack. As instituições abrigo, escola e Caps-ad configuraram

3 Nomes fictícios. 
nosso circuito de deslocamento ao "seguir" Cleide e sua trajetória no mapa da etnografia multissituada/multilocal.

Se buscávamos linearidade, o que encontramos na narrativa de Cleide foi uma miríade de lembranças, entre as quais ela não estabelecia nenhum nexo causal. Desse modo, ao ser interpelada a produzir sentidos para sua trajetória, Cleide demonstrava pouco interesse pela sua condição histórica, apenas distinguindo como "sua vida" uma sucessão de acontecimentos para ela arbitrários. Dessa maneira, ao longo dos encontros que tivemos, Cleide apresentou uma narrativa fragmentada, num fluxo semelhante a uma associação livre que, ao ser contada, ganhava materialidade e possibilidades de sentido.

Ao longo dos nossos encontros, que aconteceram de março a novembro de 2013, Cleide parecia oscilar entre uma posição de recusa à patologização do seu uso de crack, o que justificava sua baixa adesão às intervenções no campo da saúde; e a aposta na possibilidade de obter da aceitação do rótulo de "dependente" algum tipo de benefício ou privilégio. No campo da assistência social Cleide assumia suas demandas como direito. Nesse campo, sim, havia adesão e busca de reconhecimento: como cidadã em busca da regulamentação dos seus documentos, aluguel social e encaminhamento para oportunidades de emprego.

Cleide se referia a uma das pesquisadoras como " $a$ professora que faz muitas perguntas", o que indica o modo assimétrico como nossa relação havia se estabelecido. Afinal, se uma de nós era a professora, esperava-se dela correção. Talvez por isso nossa relação não tenha se constituído sob um vínculo de confiança e intimidade, e sim a partir da necessidade de produção de respostas alinhadas ao socialmente esperado. Provavelmente em decorrência disso, Cleide não nos concedera a honra de conhecer de forma profunda sua história, suas motivações e desejos.

Cleide assumira viver a vida de forma por muitos nomeada como irrefletida; para ela, de forma leve e alegre. Conseguia percorrer os trâmites institucionais que poderiam lhe auferir uma inscrição social mais adaptada aos padrões de normalização hegemônicos, contudo, não estava mobilizada a cumprir com todas as exigências desse processo. Por ora, conseguir acessar os benefícios mínimos assegurados à sua condição de "pessoa que faz da rua sua morada" era o foco dos seus interesses. A companhia do marido, também em situação de rua, significava muito, pois representava proteção e garantia de manutenção do seu modo de vida. As instituições Caps-ad, centro de saúde, abrigo e outros dispositivos da assistência social - eram acessadas quando necessário, mas as possibilidades de adesão e continuidade das intervenções propostas eram sempre ditadas por Cleide, que em sua errância e "resistência", mantinha viva a recusa a quaisquer tentativas de disciplinarização do seu corpo e da sua vida.

Célia, a segunda participante da pesquisa, tinha 42 anos quando participou do grupo de mulheres e estava há cinco fazendo uso abusivo de crack. Ao longo de oito meses, de abril a dezembro de 2013, estivemos com ela sete vezes em sua casa e em seu centro de saúde de referência. Durante esse período ela nos concedeu três entrevistas gravadas, que foram tratadas seguindo as fases de trabalho previstas, quais sejam, transcrição literal, elaboração do corpus de análise, identificação dos principais temas referidos nas narrativas e de seu conteúdo central.

No começo desse período, mesmo com os frequentes esclarecimentos sobre a etnografia e seus objetivos, materializados no Termo de Consentimento Livre e Esclarecido assinado por ela, Célia atribuíra a uma das pesquisadoras o título de "minha psicóloga". Mais tarde compreenderíamos que o status daquela relação não havia se estabelecido por meio de um contrato escrito e assinado, mas a partir de uma dinâmica relacional que as envolveu como mulheres num vínculo de intimidade e cumplicidade.

Célia, de forma surpreendente e inesperada, suspendera por conta própria o uso de crack no começo dos nossos encontros, o que nos fez pensar que algo de muito importante estava sendo produzido naquela interação. Ao longo dos encontros, ela passou a se referir a uma das pesquisadoras como "minha colega", trazendo-a para mais próximo dela. Colegas. A pesquisadora não era mais a "psicóloga" que tinha um saber e autoridade sobre ela, era agora sua "colega", sua cúmplice. Compartilhavam histórias íntimas. Numa ocasião em que sua irmã ligara para ela enquanto conversávamos, querendo ir à sua casa, Célia disse a ela que só poderia recebê-la mais tarde: "Minha colega veio aqui pra gente bater papo. A conversa da gente é uma conversa assim... oculta. Não dá pra poder ficar... é... mais de um. É só entre nós".

Somente aos poucos foi se tornando claro para nós a especificidade do vínculo que se produziu naqueles encontros. Não se tratava, por certo, de uma relação com vistas à mera coleta de dados de pesquisa, sendo possível já nesse momento vislumbrar o que Barros e Silva (2002) apontam sobre o trabalho com narrativas:

recolher histórias de vida é uma relação, não uma simples tomada de informações sobre o outro; e estabelecer uma relação se faz notadamente em todo um processo em que vínculos recíprocos de confiança e afinidades irão se formar com o tempo. (p. 138)

Nesse sentido, ainda conforme as autoras, a composição da narrativa de uma vida não decorre de uma sucessão de entrevistas com um informante, mas, sim, "de um encontro único do pesquisador com uma pessoa que aceita confiar-se a ele" (p. 138). Tal relação tornou-se uma possibilidade em decorrência do fato de que a reflexão ali colocada de algum modo dizia respeito às duas, pesquisadora e entrevistada, situadas naquele momento no mesmo nível, "em pé de igualdade". Instaurou-se assim "uma relação significativa, uma autêntica interação" (Ferrarotti, 2011, p. 97). 
Célia apresentou em sua narrativa uma relação paradoxal com a medicação prescrita no centro de saúde: ao mesmo tempo que o remédio lhe possibilitava manter-se abstinente, a mantinha "domada", apaziguada frente ao seu cotidiano insípido. Whyte, Van Der Geest e Hardon (2002), em um estudo com usuárias de benzodiazepínicos, identificaram o papel ambíguo dos medicamentos na vida das mulheres: de um lado, aumentam a dependência de consultas e são objeto de controle médico; de outro, são importantes recursos de poder, uma vez que dão a elas controle sobre suas vidas. Para Célia, o manejo que fazia da sua medicação configurava-se como um exercício de autonomia, estando relacionado aos seus episódios de uso de crack, já que estes aconteciam nos períodos em que ela se encontrava menos medicada e, portanto, mais ativa, o que fazia irromper nela desejos de mudança e superação do contexto restritivo no qual estava inserida.

\section{Discussão}

A escuta das mulheres possibilitada pela etnografia multissituada/multilocal representou o encontro com a produção de diferenças que desarticularam sentidos fixos e desafiaram as inteligibilidades orientadoras das práticas de cuidado no campo de atenção às pessoas que usam drogas. A interpelação resultante desse encontro indicou possibilidades de experiências com drogas até então desconhecidas e somente por nós compreendidas de maneira parcial e incipiente, por, entre outras coisas, desestabilizarem os ideais de normalização hegemônicos, aos quais também nos encontramos submetidos. Assim, mais do que nos fazer um convite, o movimento em direção à escuta das mulheres nos impele ao reconhecimento dos limites de nossos saberes e práticas no campo dos cuidados oferecidos às mulheres que usam drogas, inaugurando a possibilidade de um novo olhar sobre suas questões.

Foram ressaltados os limites que a condição de "usuária" de um serviço de saúde mental especializado em demandas relacionadas ao uso de drogas estabelece à enunciação de um saber válido das mulheres sobre si mesmas. Nesse sentido, as mulheres permanecem sendo vistas pelos especialistas a partir do dispositivo da medicalização (Fiore, 2002), ou seja, como sujeitos com direito à saúde e cuidados assistenciais especializados. Decorre disso que somente de maneira muito incipiente observamos sua emergência nos serviços como sujeitos cuja fala, legitimada, é considerada na elaboração das práticas profissionais do campo. Desse modo, as mulheres são alçadas à condição de objeto de uma intervenção institucional fundamentada na normalização biopolítica (Foucault, 2008), que se ocupa menos com a escuta da sua singularidade e mais com a gestão de sua saúde e corpos.

Assim, tendo em vista que os sujeitos aqui em questão são mulheres que usam drogas, nessa normalização evidenciam-se os controles exercidos de modo especial em torno dos ideais heteronormativos de vigilância sobre seus corpos, em detrimento de uma atenção focada na escuta de suas necessidades "reais". Por generalização, decorre disso que a maioria das práticas de cuidado direcionadas às mulheres no âmbito familiar são focadas no atendimento às suas necessidades alimentícias, de sono, higiene e repouso, além do encaminhamento para serviços especializados em desintoxicação, práticas vistas por elas como ações de controle sobre sua vida e punição pela sua situação de dependência (Santos \& Silva, 2012) e não como ações reconhecidamente de "cuidado".

Um apontamento fundamental que deve ser feito sobre a pesquisa etnográfica com mulheres que usam drogas numa perspectiva feminista é a indispensável explicitação do desafio que sua escuta representa para os/as pesquisadores/as. Se ir ao encontro da diferença fora algo ansiado por nós, por exemplo, efetivar esse encontro se mostrou durante todo o tempo algo da ordem daquilo que escapa, que foge à compreensão, e por isso produz a constante necessidade de assimilação a partir de esquemas teóricos previamente conhecidos. Desse modo, representou tarefa metodológica constante o esforço para evitar a atribuição de sentidos fixos às trajetórias das mulheres ou a produção de um saber sobre elas elaborado exclusivamente por nós. Portanto, configurou-se como principal desafio metodológico ao longo de todo o trabalho de campo o aprimoramento da capacidade de escutar os sentidos que as mulheres produziam sobre suas próprias experiências e sobre si mesmas, não para construir um saber sobre elas, para elas e nem mesmo com elas, mas, sim, para elaborar pela reflexividade (Neves \& Nogueira, 2005) um saber sobre nossa relação com elas, única experiência acerca da qual poderíamos ser legítimos enunciadores.

Foi a partir dessa posição como pesquisadores que pudemos, então, ver emergir na nossa experiência com mulheres que usam drogas novas e desconhecidas nomeações sobre o fenômeno que buscamos conhecer inicialmente. Assim, não encontramos em campo "usuárias", e sim "mulheres" cujas trajetórias incluíam experiências de uso de drogas, designadas por elas de formas diversas. Tais encontros proporcionaram a ampliação das nossas possibilidades de compreensão de suas singularidades, centrais para a exploração das suas formas de engajamento com o mundo e para a elaboração de possíveis estratégias de cuidado e preservação no uso de drogas.

Enfim, produziu-se nesta pesquisa um deslocamento no modo clássico de elaboração do conhecimento científico, que colocou no centro do trabalho o debate em torno das condições de produção e autoria dos saberes. Assim, é da posição de quem foi sujeito ativo da experiência em análise que podemos falar dos diferentes encontros que se deram nesta pesquisa: da frustração pela relação não estabelecida com Cleide; e da intensa relação de intimidade vivenciada com Célia. Foi a partir do real vivido que o saber elaborado neste trabalho se produziu; saber este sempre parcial, localizado e afetado pelas experiências que nos constituíram como pesquisadores. 


\section{Conclusões}

Ao assumir a escuta direta das mulheres como recurso metodológico, colocamo-nos em coerência com uma inscrição epistemológica que valoriza a reflexividade e a experiência como vias de acesso ao político. Tal escolha também inscreveu o estudo aqui realizado no bojo das pesquisas críticas ao modo como se constituem as hierarquias na produção do conhecimento científico. É, portanto, a partir do questionamento dos ideais de neutralidade e objetividade e da valorização da posicionalidade e envolvimento do pesquisador como vias de acesso à experiência - entendida como resultado de processos históricos e discursivos - que acreditamos poder ser criadas as condições para o desenvolvimento de pesquisas e intervenções mais eficazes no campo da saúde.

$\mathrm{O}$ caminho metodológico traçado apresentou desafios decorrentes das exigências que lhe são próprias, entre eles, os custos de uma inscrição necessariamente longa em campo, essencial para o estabelecimento de vínculos íntimos e possibilitadora do acesso ao cotidiano dos sujeitos envolvidos para além dos espaços institucionais por onde circulam com nomeações fixas.

Outra questão levantada por este trabalho diz respeito à compreensão de que as diversas características de contexto social, histórico e cultural exigem práticas e instrumentos psicológicos que precisam ser criados e reinventados a partir, especialmente, da utilização de metodologias através das quais se faça possível a escuta dos sujeitos envolvidos. Nesse sentido, é mister interrogar se as condições de opressão podem dar lugar a expressões políticas de fala, entendidas como a articulação de narrativas não capturadas pelos sentidos e compreensões dominantes. O que está posto, portanto, é a premência de que os próprios sujeitos possam falar por si mesmos sobre suas experiências e enunciar seus direitos, e a necessidade de construirmos metodologias de pesquisa e intervenção coerentes com essa proposta.

Para encerrar, cabe mencionar que ainda que a psicologia venha estudando os processos de exclusão/inclusão social num esforço consciente de colaborar com a garantia de direitos e, portanto, criar condições para o exercício pleno da cidadania, pela perspectiva excessivamente individualizante com que tem abordado esse tema, assim como por muitas de suas concepções de sujeito, ela frequentemente colabora com os processos de exclusão social. Reconhecer os dilemas políticos que constituem os fenômenos psicológicos, com vistas à problematização do caráter universal de como a psicologia tem lidado historicamente com as diferenças, torna-se portanto necessário para romper com a lógica essencialista presente em seu trabalho nas políticas públicas, sendo este um dos principais desafios éticos da psicologia no campo dos direitos das pessoas que usam drogas.

\title{
Narrative research with drug-using women: a feminist ethnographic experience
}

\begin{abstract}
This is a narrative research, inserted in the feminist epistemological field, that sought to know the life trajectory of women who use crack. A multi-sited ethnographic research was carried out, which started from listening to drug-using women who took part in a public mental health service to, then, following two of them through the spaces in which they lived, namely, shelter, school, health center, in addition to their own homes. The narrative interview technique was used as data collection method. The act of listening to the women allowed us to disarticulate fixed meanings and challenge the guiding intelligibility of care practices to people who use drugs. The limitations that the condition of user of a mental health service establishes to the enunciation of a valid knowledge of the women about themselves stood out, as their narratives are a product of the discourse created about them by the health field, which institutes and prescribes their own materialization as drug users.
\end{abstract}

Keywords: drug-using women, feminist epistemology, ethnography, narrative interview.

\section{Recherche narrative avec les femmes utilisatrices de drogues: une expérience féministe ethnographique}

Résumé: Ce travail est une recherche narrative inscrite dans le domaine épistémologique féministe, qui a cherché connaitre les trajectoires de vie des femmes utilisatrices de crack cocaine. Une ethnographie multi-située à été conduite, en commençant par écouter les utilisatrices insérées dans un service de santé mentale publique, pour à la suíte suivre deux d'entre elles dans les espaces à travers lesquels elles circulent, à savoir l'école et les établissements de santé en plus de leur propres logements. Comme méthode de collecte des données, la technique d'entrevue narrative a été utilisée. L'écoute des femmes a permis le démantèlement des signifiants fixes et remis en cause les intelligibilités dirigeant les pratiques de soins aux personnes qui consomment des drogues. On a mis en évidence les limites que la condition d'utilisateur d'un service de santé mentale imposent sur l'énoncé d'une connaissance valable des femmes sur elles-mêmes, leurs narratifs étant un produit du discours elaboré sur elles par le système de santé, qui établit et prescrit leur matérialisation en tant qu'utilisatrices de drogues.

Mots-clés: femmes utilisatrices de drogues, épistémologie féministe, ethnographie, entretien narratif. 


\section{La investigación narrativa con mujeres que utilizan drogas: una experiencia etnográfica desde la perspectiva feminista}

Resumen: Se trata de una investigación narrativa inscrita en el campo epistemológico de perspectiva feminista, no cual buscó conocer las trayectorias de vida de mujeres usuarias de crack. Se realizó una etnografía multisituada / multilocal, que partió de la escucha de usuarias insertadas en un servicio público de salud mental para luego seguir dos dellas por los espacios por los cuales circulaban, cuáles son, la calle, escuela, equipamientos de salud, además de sus propias casas. Como método de recolección de datos se utilizó la técnica de entrevista narrativa. La escucha de las mujeres posibilitó la desarticulación de sentidos fijos y desafió las inteligibilidades orientadoras de las prácticas de cuidado a las personas que usan drogas. Se resalta los límites que la condición de usuaria de un servicio de salud mental establece la enunciación de un saber válido de las mujeres sobre sí mismas, siendo sus narrativas producto del discurso sobre ellas elaborado por el campo de la salud, que instituye y prescribe su propia materialización como usuarias de drogas.

Palabras clave: usuárias de drogas, epistemologia feminista, etnografia, investigación narrativa.

\section{Referências}

Barros, R. B. (2007). Grupo: a afirmação de um simulacro. Porto Alegre, RS: Sulina, Editora da UFRGS.

Barros, V. A., \& Silva, L. R. (2002). A pesquisa em história de vida. In I. B. Goulart (Org.). Psicologia organizacional e do trabalho: teoria, pesquisa e temas correlatos (pp. 133-146). São Paulo, SP: Casa do Psicólogo.

Braidotti, R. (2002). Diferença, diversidade e subjetividade nômade. Labrys, estudos feministas, 1(2), 1-16.

Brandão, T. O., \& Germano, I. M. P. (2009). Experiência, memória e sofrimento em narrativas autobiográficas de mulheres. Psicologia e Sociedade, 21(1), 5-15.

Brasil. (2012). Ministério da Saúde. Portaria $n^{o} 130$, de 26 de janeiro de 2012. Redefine o Centro de Atenção Psicossocial de Álcool e outras Drogas $24 \mathrm{~h}$ (CAPS AD III) e os respectivos incentivos financeiros. Brasília, DF: Gabinete do Ministro.

Bruner, J. (1997). Atos de significação. Porto Alegre, RS: Artes Médicas.

Butler, J. (2006). Deshacer el género. Barcelona, España: Paidós.

Castro, L. R. (2011). Os jovens podem falar? Sobre as possibilidades políticas de ser jovem hoje. In J. Dayrell, M. I. C. Moreira, \& M. Stengel (Orgs.), Juventudes contemporâneas: um mosaico de possibilidades (pp. 299-324). Belo Horizonte, MG: PUC Minas.

Ferrarotti, F. (2011). Las historias de vida como método. Acta Sociológica, 56, 95-119.

Fiore, M. (2002, out.). Algumas reflexões a respeito dos discursos médicos sobre uso de "drogas". Trabalho apresentado no XXVI Encontro Anual da Anpocs, Caxambu, MG.

Fischer, M. (2011). Futuros antropológicos: redefinindo a cultura na era tecnológica. Rio de Janeiro, RJ: Zahar.

Foucault, M. (1987). Vigiar e punir: nascimento da prisão. Petrópolis, RJ: Vozes.

Foucault, M. (1988). História da sexualidade I: a vontade de saber. Rio de Janeiro, RJ: Graal.

Foucault, M. (1999). Em defesa da sociedade. São Paulo, SP: Martins Fontes.
Foucault, M. (2008). Nascimento da biopolítica: curso dado no Collège de France (1978-1979). São Paulo, SP: Martins Fontes.

Geertz, C. (1978). Uma descrição densa: por uma teoria interpretativa da cultura. In A interpretação das culturas (pp. 3-21). Rio de Janeiro, RJ: Zahar.

Germano, I. M. P., \& Silva Serpa, F. A. (2008). Narrativas autobiográficas de jovens em conflito com a lei. Arquivos Brasileiros de Psicologia, 60(3), 9-22.

Haraway, D. (2009). Manifesto ciborgue: ciência, tecnologia e feminismo-socialista no final do século XX. In $\mathrm{T}$. Tadeu (Org.), Antropologia do ciborgue: as vertigens do pós-humano (pp. 33-118). Belo Horizonte, MG: Autêntica.

Harding, S. (1987). Introduction: is there a feminist method? In S. Harding, Feminism and methodology: social science issues (pp. 1-14). Bloomington, USA: Indiana University Press.

Josso, M.-C. (2006). Os relatos de história de vida como desvelamento dos desafios existenciais da formação e do conhecimento: destinos socioculturais e projetos de vida programados na invenção de si. In E. C. Souza \& M. H. M. B. Abrahão (Orgs.), Tempos, narrativas e ficções: a invenção de si (pp. 21-40). Porto Alegre, RS: EdiPUCRS.

Longino, H. (1987). Can there be a feminist science? Hypatia, 2(3), 51-64.

Machado, L. Z. (1994). Campo intelectual e feminismo: alteridade e subjetividade nos estudos de gênero (Série Antropologia 170). Brasília, DF: Departamento de Antropologia da UnB.

Marcus, G. (2001). Etnografía en/del sistema mundo. El surgimiento de la etnografia multilocal. Alteridades, 11(22), 111-127.

Neves, S., \& Nogueira, C. (2005). Metodologias feministas: a reflexividade ao serviço da investigação nas ciências sociais. Psicologia: Reflexão e Crítica, 18(3), 408-412. Recuperado de https://bit.ly/2s $8 \mathrm{NPFj}$ 
Pereira, M. (2009). Esta é a minha casa: a intersecção entre a raça e o género no romance Brick Lane de Monica Ali e no filme de Sarah Gavron. Ex aequo, 19, 71-85.

Prado, M. A. M., \& Queiroz, I. S. (2012). A emergência da politização da intimidade na experiência de mulheres usuárias de drogas. Estudos de Psicologia, 17(2), 305-312. Recuperado de https://bit.ly/2kuaIzj

Queiroz, I. S. (2015). Norma de gênero e uso de drogas: normalização e diferença na experiência de mulheres (Tese de doutorado). Faculdade de Filosofia e Ciências Humanas, Universidade Federal de Minas Gerais, Belo Horizonte.

Rich, A. (2002). Notas para uma política da localização. In A. G. Macedo (Org.), Género, identidade e desejo: antologia crítica do feminismo contemporâneo (pp. 15-35). Lisboa, Portugal: Cotovia.

Rocha, M. L., \& Aguiar, K. F. (2003). Pesquisa-intervenção e a produção de novas análises. Psicologia: Ciência e Profissão, 23(4), 64-73.

Saffioti, H. (1991). Novas perspectivas metodológicas de investigação das relações de gênero. In M. A. M. Silva (Org.), Mulher em 6 tempos. Araraquara, SP: Unesp.

Santos, A. M., \& Silva, M. R. S. (2012). A experiência de cuidar da mulher alcoolista na família. Revista da escola de enfermagem da USP, 46(2), 364-371. Recuperado de https://bit.ly/2scWMNQ

Schutze, F. (1992). Pressure and guilt: war experiences of a young german soldier and their biographical implications. Part 1. Internacional Sociology, 7(2), 187-208.

Scott, J. W. (1999). Experiência. In A. L. Silva, M. C. S. Lago, \& T. R. O. Ramos (Orgs.), Falas de gênero (pp. 21-55). Santa Catarina, SC: Editora Mulheres. Recuperado de http://historiacultural.mpbnet.com.br/feminismo/Joan Scoot-Experiencia.pdf
Silva, T. T. (1993). Sociologia da educação e pedagogia crítica em tempos pós-modernos. In T. T. Silva (Org.), Teoria educacional crítica em tempos pós-modernos (pp. 122-142). Porto Alegre, RS: Artes Médicas.

Spink, M. J. P., \& Medrado, B. (2004). Produção de sentidos no cotidiano: uma abordagem teórico-metodológica para análise das práticas discursivas. In M. J. P. Spink (Org.), Práticas discursivas e produção de sentidos no cotidiano: aproximações teóricas e metodológicas (3a ed., pp. 41-61). São Paulo, SP: Cortez.

Spivak, G. (1987). Can the subaltern speak. In C. Nelson \& L. Grossberg (Eds.), Marxism and the interpretation of culture (pp. 271-313). Chicago: University of Illinois Press.

Vargas, R. B. A. (2012). A saúde integral das mulheres e a educação médica: uma ponte por construir (Dissertação de Mestrado). Programa de Pós-Graduação em Sociologia, Universidade Federal do Rio Grande do Sul, Porto Alegre.

Victora, C., \& Knauth, D. R. (2004). Corpo, gênero e saúde: a contribuição da antropologia. In M. N. Strey \& S. T. L. Cabeda (Orgs.), Corpos e subjetividades em exercício interdisciplinar (Coleção Gênero e Contemporaneidade 3). Porto Alegre, RS: EdiPUCRS.

Whyte, S. R., Van Der Geest, S., \& Hardon, A. S. (2002). Woman in distress: medicines for control. In S. R. Whyte, S. Van Der Geest, \& A. S. Hardon. (Orgs.), Social lives of medicines (pp. 50-63). Cambridge: Cambridge University Press.
Recebido: 28/03/2018

Aprovado: 06/04/2018 